
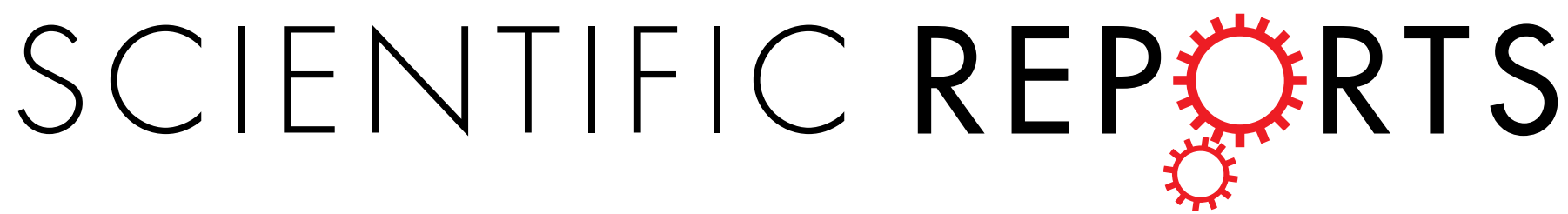

\title{
OPEN
}

Received: 19 June 2018

Accepted: 4 December 2018

Published online: 04 February 2019

\section{Structural biology workflow for the expression and characterization of functional human sodium glucose transporter type 1 in Pichia pastoris}

\author{
Albert Suades ${ }^{1,4}$, Antonio Alcaraz ${ }^{2}$, Esteban $\mathrm{Cruz}^{1}$, Elena Álvarez-Marimon ${ }^{1}$, \\ Julian P. Whitelegge ${ }^{3}$, Joan Manyosa ${ }^{1}$, Josep Cladera ${ }^{1}$ \& Alex Perálvarez-Marín ${ }^{1}{ }^{1}$
}

Heterologous expression of human membrane proteins is a challenge in structural biology towards drug discovery. Here we report a complete expression and purification process of a functional human sodium/D-glucose co-transporter 1 (hSGLT1) in Pichia pastoris as representative example of a useful strategy for any human membrane protein. hSGLT1 gene was cloned in two different plasmids to develop parallel strategies: one which includes green fluorescent protein fusion for screening optimal conditions, and another for large scale protein production for structural biology and biophysics studies. Our strategy yields at least $1 \mathrm{mg}$ of monodisperse purified recombinant hSGLT1 per liter of culture, which can be characterized by circular dichroism and infrared spectroscopy as an alpha-helical fold protein. This purified hSGLT1 transports co-substrates ( $\mathrm{Na}^{+}$and glucose) and it is inhibited by phlorizin in electrophysiological experiments performed in planar lipid membranes.

Membrane proteins play key roles in a wide range of cellular processes in eukaryotic and prokaryotic cells, accounting for $20-30 \%$ of the genome coding proteins ${ }^{1,2}$. Human membrane proteins are obviously relevant as biomarkers for diseases caused by protein malfunctioning and as the principal targets for pharmacological intervention $^{3,4}$. Knowledge on the tridimensional structure of membrane proteins aids the design of drugs to open therapeutic intervention windows but despite the efforts and several structural biology breakthroughs, few structures of human membrane proteins have been resolved ${ }^{5,6}$. Challenging as it is, the structural biology of membrane proteins poses a major challenge, which is the expression and isolation of functional human membrane proteins. Choice of recombinant expression host can be crucial for structure determination of human membrane proteins ${ }^{7}$. Human membrane proteins are poorly expressed heterologously in prokaryote systems, facing obstacles such as post-translational modifications ${ }^{8}$. Thus, eukaryotic systems are better suited for human membrane protein expression, and so far the most successful system-of-choice has been insect cells ${ }^{7}$. Yeast has been the second-best heterologous expression system, and within yeast, Pichia pastoris has been the most successful ${ }^{7,9}$. $P$. pastoris has several advantages compared to insect cells for expression of large membrane protein amounts, especially regarding lab handling, molecular biology, and instrumentation requirement ${ }^{10,11}$. All these advantages allow better screening of expression and isolation conditions. Other successful structural biology screening strategies have been developed to optimize the purification process towards the final goal of tridimensional structure resolution, such as the use of green fluorescent protein (GFP) quicker screening of expression and solubilization conditions ${ }^{12-14}$. Integration of several experimental approximations is key to define successful strategies for the structural biology of human membrane proteins.

Human sodium glucose transporter 1 (hSGLT1) belongs to the solute sodium symporters (SSS) subfamily within Amino acid-Polyamine-organoCation (APC) superfamily of transporters. hSGLT1 is a member of the SLC5 gene family and was the first member to be cloned ${ }^{15}$. This transporter has been widely studied and related to

${ }^{1}$ Biophysics Unit, Department of Biochemistry and Molecular Biology, School of Medicine, Universitat Autònoma de Barcelona, 08193, Cerdanyola del Vallés, Catalonia, Spain. ${ }^{2}$ Laboratory of Molecular Biophysics, Department of Physics, Universitat Jaume I, 12071, Castellón, Spain. ${ }^{3}$ The Pasarow Mass Spectrometry Laboratory, The NPI-Semel Institute, David Geffen School of Medicine, UCLA, 760 Westwood Plaza, Los Angeles, CA, 90095, USA. ${ }^{4}$ Present address: Department of Biochemistry and Biophysics, Stockholm University, SE-10691, Stockholm, Sweden. Correspondence and requests for materials should be addressed to A.P.-M. (email: alex.peralvarez@uab.cat) 


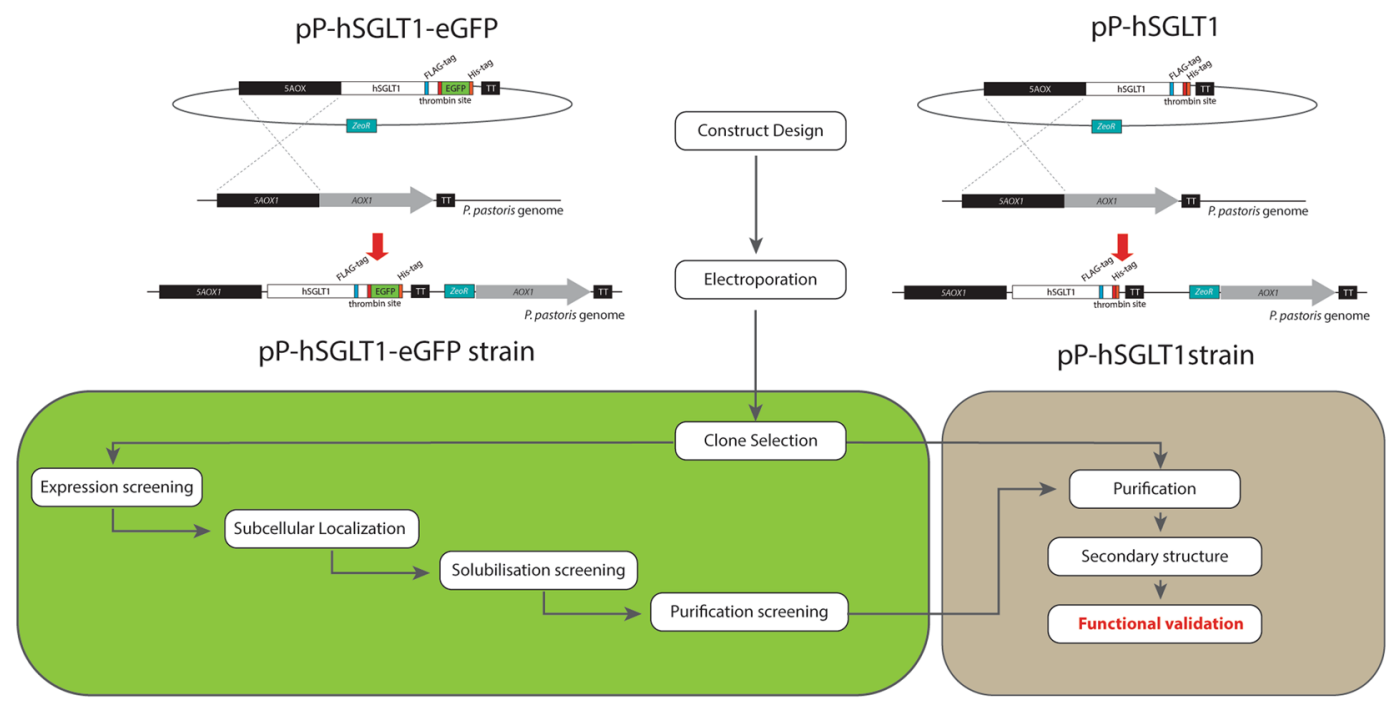

Figure 1. Overview of the hSGLT1 expression and characterization strategy. Notice the parallel strategy using the pP-hSGLT1-eGFP and pP-hSGLT1 vectors.
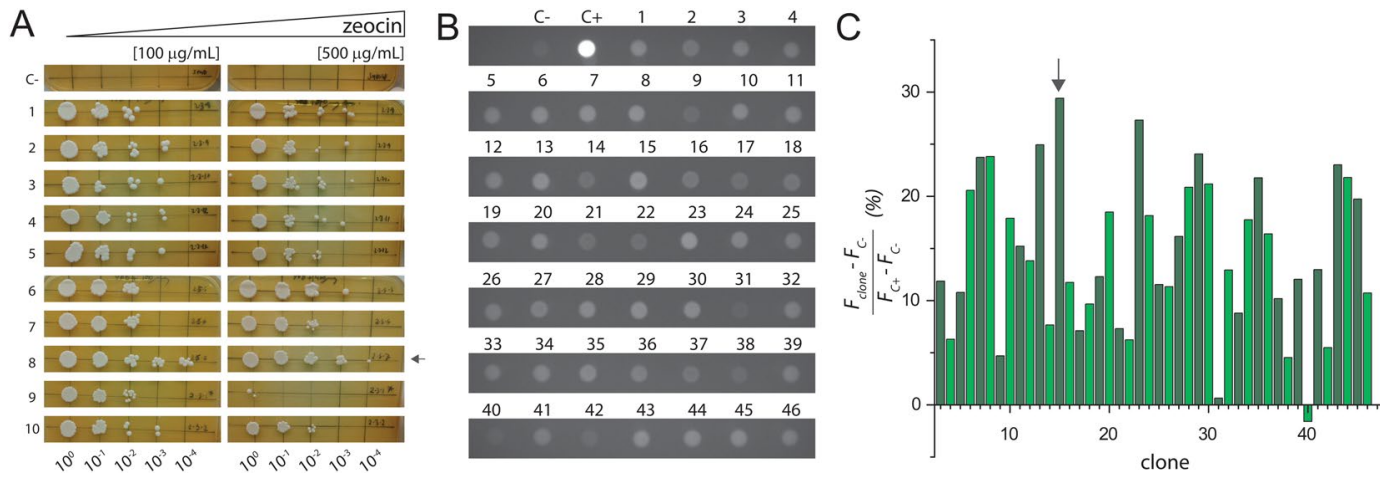

Figure 2. Clone selection. (A) Drop test in YPD plates with $100 \mu \mathrm{g} / \mathrm{mL}$ and $500 \mu \mathrm{g} / \mathrm{mL}$ of zeocin after $2-3$ days of growth at $30^{\circ} \mathrm{C}$. On the left, plates with $100 \mu \mathrm{g} / \mathrm{mL}$ zeocin and, on the right, plates with $500 \mu \mathrm{g} / \mathrm{mL}$ zeocin. Each plate presented a non-transformed SMD1168H serial dilution as negative control $(\mathrm{C}-$ ). Each number represents a tested clone and $(\mathrm{C}-$ ) a non-transformed SMD1168H colony. A dilution factor of 10x was done for each lane, starting from left to right. (B) MM plates after 48 hours at $30^{\circ} \mathrm{C}$. Each dot represents a different tested clone from pP-hSGLT1-eGFP transformation except the controls $(\mathrm{C}-)$ and $(\mathrm{C}+)$. Negative control $(\mathrm{C}-)$ is a non-transformed SMD1168H P. pastoris colony. Positive control $(\mathrm{C}+)$ is a transformed colony of pP-eGFP empty vector. (C) Densitometry values of tested colonies are expressed in relative fluorescence units (RFU).

diseases, such as Glucose-Galactose Malabsorption (GGM) or diabetes ${ }^{16,17}$. The structure for hSGLT1 could not be solved because poor expression levels were achieved, but the prokaryote orthologue from Vibrio parahaemolyticus (vSGLT) has been crystallized and the structure resolved ${ }^{18}$. Although the prokaryotic vSGLT structure is a relevant model, advances in the structure determination for hSGLT1 are key for human therapy and pharmacology drug design purposes. Here we report a full screening strategy (from expression host for protein source to functional protein validation) towards biophysical and structural biology studies for the expression of hSGLT1 which may be useful for any other membrane electrogenic transport proteins (Fig. 1).

\section{Results}

Selection of multiple copy recombinant genes of $\boldsymbol{P}$. pastoris transformants. Linearized vector containing hSGLT1 was electroporated in SMD1168H to promote integration in the AOX locus of $P$. pastoris genome (Fig. 1) allowing for positive insertion events using zeocin. Clone screening using a serial dilution at low $(100 \mu \mathrm{g} / \mathrm{mL})$ and high $(500 \mu \mathrm{g} / \mathrm{mL})$ zeocin concentration allows the selection of multiple integration events due to variable number of copies of the bleomycin gene, which drives zeocin resistance. For pP-hSGLT1, a serial dilution in YPD medium with zeocin was done (Fig. 2A). Non-transformed SMD1168H as negative control did not grow while the rest of tested transformed clones did grow.

All tested clones grew in presence of $100 \mu \mathrm{g} / \mathrm{mL}$ of zeocin, but Clone 8 grew in the last dilution $\left(10^{-4}\right)$. Clone 8 fitness was confirmed at $500 \mu \mathrm{g} / \mathrm{mL}$ of zeocin and, therefore, the C8 strain was selected for protein expression. 

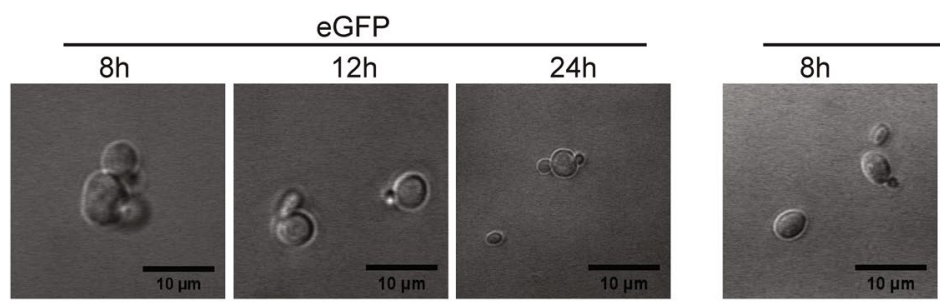

hSGLT1-eGFP
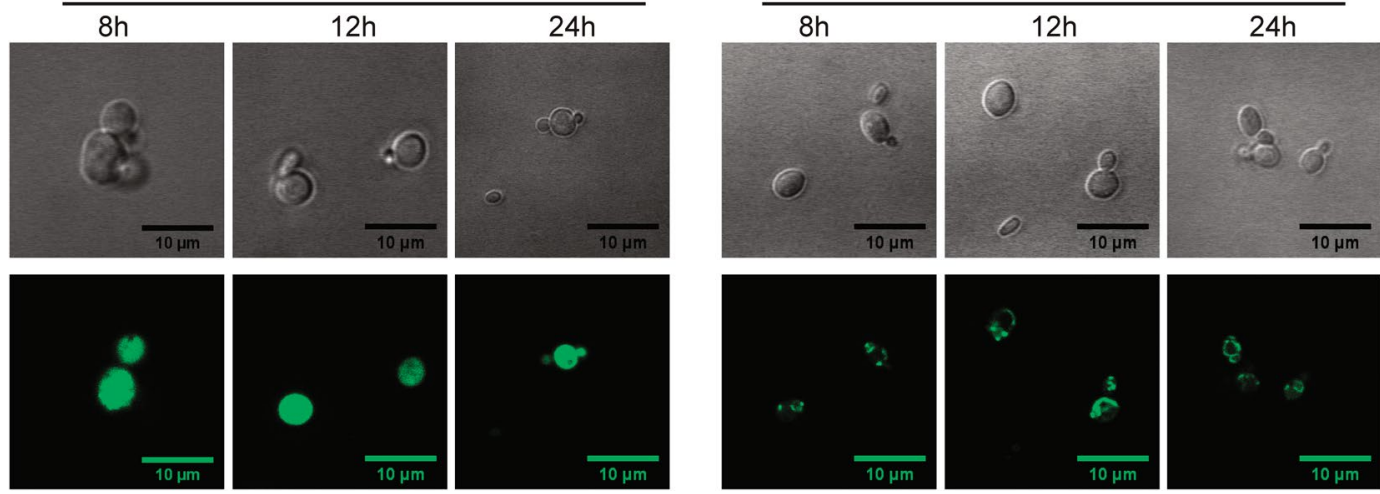

Figure 3. GFP fluorescence for subcellular localization. Representative fields of pP-eGFP (eGFP) and pPhSGLT1-eGFP (hSGLT1-eGFP) strains after methanol induction in MM media at: 8, 12 and 24 hours from left to right. A bright field image is on the top and each corresponding confocal image is represented on the bottom.

For pP-hSGLT-eGFP, in plate protein expression induction method was done and we were able to select clones using the fluorescence due to GFP expression (Fig. 2B). The negative control (non-transformed SMD1168H) observed in the plate reflects the intrinsic fluorescence of cells (background noise) while the positive control (pP-eGFP empty vector) expressing soluble eGFP (brightest in Fig. 2B) allows to set a relative fluorescence maximum for quantification (Fig. 2C), which reveals Clone 15 as the most intense amongst the ones transformed with pP-hSGLT-eGFP.

Subcellular protein localization. Protein expression of pP-hSGLT-eGFP was analyzed by confocal microscope and compared to GFP expression (Fig. 3). GFP expression shows a diffuse pattern of expression typical for a soluble protein while hSGLT1-eGFP displays a fluorescence that is more localized in dots or patches, corresponding to the expression of proteins in membrane compartments.

Detergent screening. Membranes of pP-hSGLT1-eGFP solubilized in different detergents (Fig. 4A) were subjected to FSEC in a Superose 6 gel filtration column (Fig. 4B). The FSEC profiles for representative detergents are shown in Fig. 4B. Most of the detergents show a chromatogram with free eGFP as the predominant form ( $>35$ minutes elution time), except for Fos-12, which solubilized hSGLT1-eGFP the most (Fig. 4A) and shows a predominant peak at $30 \mathrm{~min}$. elution time in FSEC profile (Fig. 4B), corresponding to hGSLT1-eGFP. Accordingly, Fos- 12 was the detergent-of-choice for protein solubilization.

Protein purification. Taking advantage of the eGFP fluorescence, we used the pP-hSGLT1-eGFP strain for optimization of protein expression, detergent screening and subcellular protein localization. The obvious follow-up strategy is to use the pP-hSGLT-eGFP strain to scale-up the protein purification process and remove the eGFP and 8 XHis tags in subsequent steps by using proteases (Fig. 1). However, for this specific strain the thrombin digestion to remove the tags is not efficient enough (data not shown). At the point when all screenings have been made, it is important to have a contingency plan to proceed with the hSGLT1 protein purification. Thus, for large-scale protein purification we used the pP-hSGLT strain using the conditions for expression, and solubilization screened with the pP-hSGLT1-eGFP strain. Enrichment of hSGLT1 from Ni-NTA IMAC purification (Fig. S1A) eluted at $150 \mathrm{mM}$ imidazole were pooled, concentrated and injected into a Superdex S200 gel filtration column (Fig. 5A). A homogenous single peak of protein is appreciated in the SEC centered at $11 \mathrm{~mL}$ and with a small shoulder at $9.5 \mathrm{~mL}$. Fractions loaded in a SDS-PAGE are represented in Fig. 5A. The material loaded in the gel filtration (L) showed a single diffused band with an apparent molecular weight of $55 \mathrm{kDa}(\mathrm{main}$ protein-band in the Ni-NTA). To discard the effect of potential protein glycosylation, we mutated Asn248 to Ala and no remarkable effects were observed in SEC nor SDS-PAGE (Fig. S1B). In the first elution fraction (1, Fig. 5A), several bands are appreciated at: $150 \mathrm{kDa}, 80 \mathrm{kDa}, 75 \mathrm{kDa}$ and $55 \mathrm{kDa}$. In subsequent fractions (2 and 3 , Fig. 5A), the higher molecular weight band at $150 \mathrm{kDa}$ vanishes while other bands ( 80 and $75 \mathrm{kDa})$ decay in intensity (4, Fig. 5A) but the diffused band at $55 \mathrm{kDa}$ increases in intensity. A lower molecular weight band is also observed at $37 \mathrm{kDa}$. Those two bands increase in intensity in later fractions (4 and 5, Fig. 5A) while the main diffused band at $55 \mathrm{kDa}$ starts to fade. In F3, it can be appreciated that two thin and low intensity bands are observed at $50 \mathrm{kDa}$ which were mixed with this main diffused band at $55 \mathrm{kDa}$. Rough molecular weight estimation using gel filtration standards (Fig. S1C) indicates that the 9.5 and $11 \mathrm{~mL}$ fractions in Fig. 5A correspond to large protein-detergent complexes at 376 and $204 \mathrm{kDa}$, respectively (Fig. S1D). Taking advantage of the FLAG tag engineered within the ORF of hSGLT1 (Fig. 1), we performed a polishing step using a FLAG-Tag resin after Ni-NTA IMAC and prior to Superdex S200 gel filtration (Fig. 5B), in order to remove the impurities observed in Fig. 5A. The chromatogram in Fig. 5B is more monodisperse and the shoulder at $9.5 \mathrm{~mL}$ is less intense than the chromatogram shown in Fig. 5A. Fractions loaded in an SDS-PAGE indicate that protein bands were washed out $(100 \mathrm{kDa}, 75 \mathrm{kDa}$ and $37 \mathrm{kDa}$ bands Fig. $5 \mathrm{~B})$ compared to after Ni-NTA enrichment in Fig. 5A. Nevertheless, fraction from the shoulder at $9.5 \mathrm{~mL}$ ( 1 and 2, Fig. 5A) revealed a diffuse band between $150 \mathrm{kDa}$ and $250 \mathrm{kDa}$, also present in Fig. 5B. The main band with an apparent molecular weight of $55 \mathrm{kDa}$, corresponding to hSGLT1 

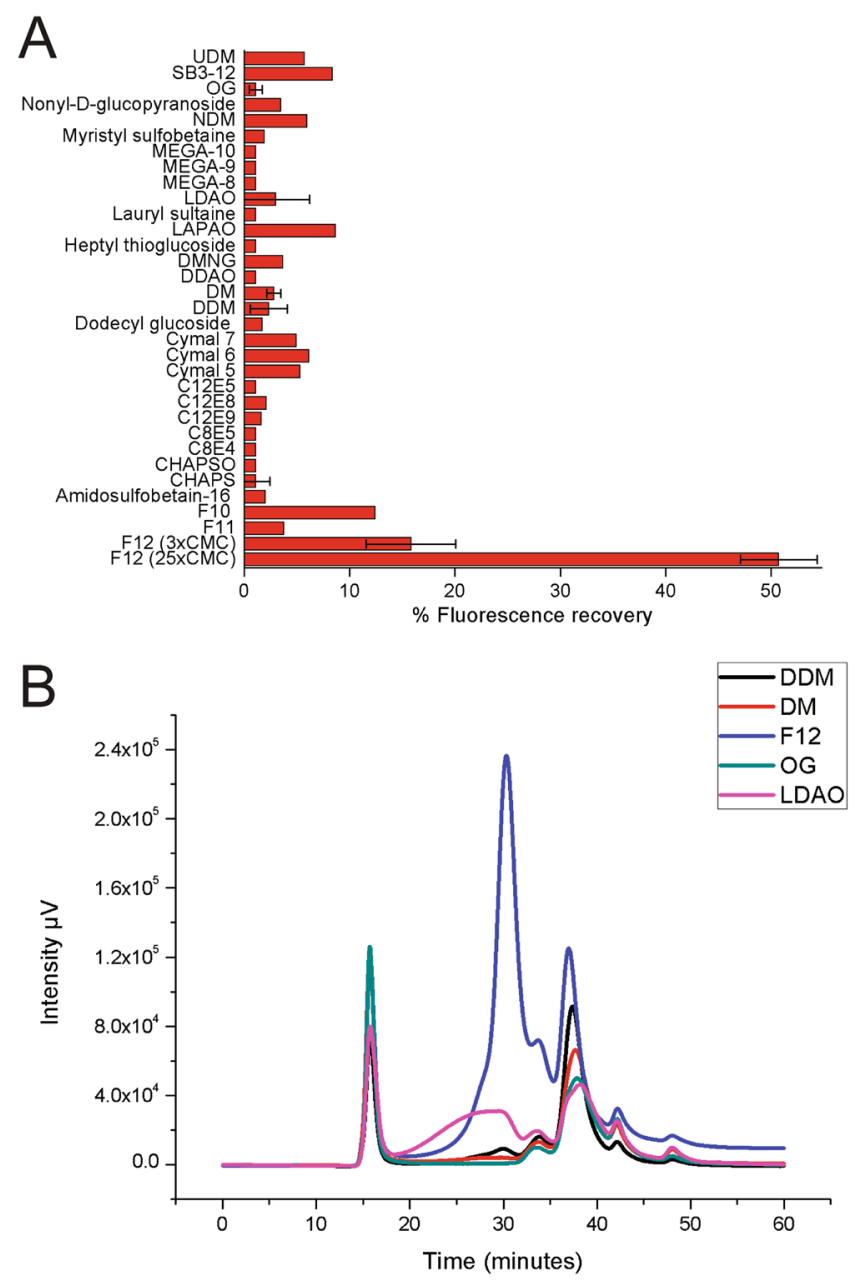

Figure 4. Detergent screening. (A) Percentage of fluorescence of solubilized membranes compared to lysate total fluorescence after solubilization with different detergents. Samples were read in a plate reader with a combination of excitation and emission filters of $485 / 520 \mathrm{~nm}$, respectively. UDM (n-Undecyl$\beta$-D-Maltopyranoside), SB3-12 (Sulfobetaine 3-12), OG (Octyl- $\beta$-Glucoside), NDM (n-Nonyl- $\beta$-DMaltopyranoside), MEGA 8, 9, 10 (N-Octanoyl, N-nonanoyl, N-decadyol)-(N-Methylglucamine), LDAO (N,N-Dimethyldodecylamine N-Oxide), LAPAO (3-Dodecylamido-N, N'-Dimethylpropyl Amine Oxide), DMNG (Decyl Maltose Neopentyl Glycol), DDAO (Decyldimethylamine-N-Oxide), DM (Decyl- $\beta$-DMaltopyranoside), DDM (Dodecyl- $\beta$-D-Maltoside), Cymal 7 (7-Cyclohexyl-1-Heptyl- $\beta$-D-Maltoside), Cymal 6 (6-Cyclohexyl-1-Hexyl- $\beta$-D-Maltoside), Cymal 5 (5-Cyclohexyl-1-Pentyl- $\beta$-D-Maltoside), C12E5 (Dodecyl Pentaethylene Glycol Ether), C12E8 (Octaethylene Glycol Monododecyl Ether), C12E9 (Dodecyl Nonaethylene Glycol Ether), C8E5 (Tetraethylene Glycol Monooctyl Ether), C8E5 (Octyl Pentaethylene Glycol Ether), CHAPS (3-[(3-Cholamidopropyl) Dimethylammonio]-1-Propanesulfonate), CHAPSO (3-[(3-Cholamidopropyl) Dimethylammonio]-2-Hydroxy-1-Propanesulfonate), F10 (n-Decylphosphocholine), F11 (n-Undecylphosphocholine), F12 (n-Dodecylphosphocholine). (B) FSEC chromatogram in a Superdex 200 HR column of membranes solubilized for 2 hours with selected detergents at $1 \%(\mathrm{w} / \mathrm{v})$ concentration.

(ca. $75 \mathrm{kDa}$ by mass spectrometry, Fig. S1E) appears after the first elution in Fig. 5B. In addition, to monitor our protein of interest we performed immunodetection of the hSGLT1-eGFP fusion protein (anti-eGFP yielding a band at apparent molecular weight of $75 \mathrm{kDa}$, Fig. S2), and the hSGLT1 protein (anti-hSGLT1 and anti-His-tag yielding apparent molecular weight bands of $55 \mathrm{kDa}$, Figs S3 and S4, respectively). The yield of $1 \mathrm{mg} / \mathrm{L}$ of purified monodisperse hSGLT1 protein was obtained after Ni-NTA, FLAG-tag and gel filtration purification and 1-2 mg/L were obtained after Ni-NTA and gel filtration.

Secondary structure of Fos-12 solubilized hSGLT1. To assess the secondary structure of Fos-12 solubilized hSGLT1 (Fig. 6), we used circular dichroism (CD, Fig. 6A) and ATR-FTIR spectroscopies (Fig. 6B). CD spectrum for Fos-12 solubilized hSGLT1 (Fig. 6A) shows a characteristic $\alpha$-helix structure indicated by the 210 and $222 \mathrm{~nm}$ minima. Secondary structure was estimated using K2D2 (27) and the calculated proportions secondary structures were: $85 \% \alpha$-helix, $14 \% \beta$-sheet and $1 \%$ unordered, respectively. The $4000-1000 \mathrm{~cm}^{-1}$ ATR-FTIR spectrum provides detail on specific molecular details of the sample, such as amide I, II and Fos-12 (PO ${ }^{-1}$ and $\mathrm{C}-\mathrm{H}$ ) stretching (indicated in Fig. 6B). The amide I $\left(1700-1600 \mathrm{~cm}^{-1}\right)$ is widely used to assess protein secondary 

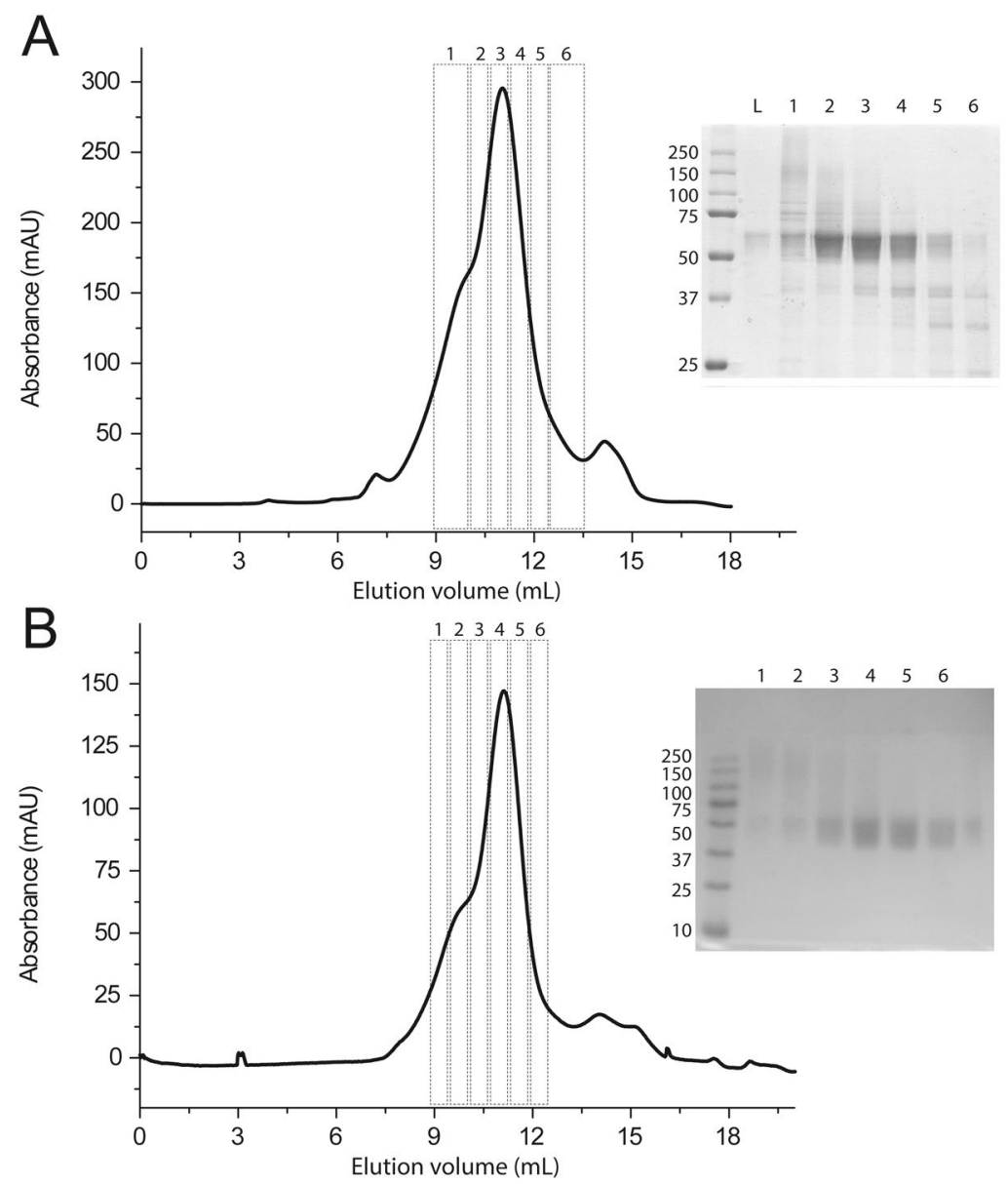

Figure 5. hSGLT1 purification. (A) SEC chromatography after Ni-NTA purification of WT-hSGLT1 with a Superdex $200 \mathrm{HR}$ column of $25 \mathrm{~mL}$ and its corresponding SDS-PAGE on the right. Protein was run in TKCL at $0.2 \%(\mathrm{w} / \mathrm{v})$ of Fos- 12 at a flow of $0.4 \mathrm{~mL} / \mathrm{min}$. SEC collected fractions of $500 \mu \mathrm{L}(2-5)$ and $1 \mathrm{~mL}(1$ and 6$)$ are represented on the SDS-PAGE. (B) SEC chromatography after Ni-NTA and FLAG-tag purification of WThSGLT1 with a Superdex $200 \mathrm{HR}$ column of $25 \mathrm{~mL}$ and its corresponding SDS-PAGE on the right. Protein was run in TKCL at $0.2 \%(\mathrm{w} / \mathrm{v})$ of Fos -12 at a flow of $0.4 \mathrm{~mL} / \mathrm{min}$. SEC collected fractions of $500 \mu \mathrm{L}(1-6)$ were loaded and resolved in a SDS-PAGE.

structure. In Fig. 6C we show the dry spectrum for Fos-12 solubilized hSGLT1 (grey line) and the band narrowing deconvolution (red line). Before deconvolution, a main peak is observed at $1650 \mathrm{~cm}^{-1}$ with a shoulder at $1630 \mathrm{~cm}^{-1}$. The $1650 \mathrm{~cm}^{-1}$ peak is characteristic of $\alpha$-helix while the peak at around $1630 \mathrm{~cm}^{-1}$ is typical from $\beta$-sheet structure and, after deconvolution, those peaks are resolved successfully: $\alpha$-helix peak is exactly at 1657 $\mathrm{cm}^{-1}$ while $\beta$-sheet peak is at $1635 \mathrm{~cm}^{-1}$. In summary, both methods show a predominantly $\alpha$-helix secondary structure for Fos-12 solubilized hSGLT1, being higher in the sample in solution analyzed by CD compared to the dry sample by ATR-FTIR.

Glucose transport by hSGLT1 in planar lipid membranes. The activity of Fos-12 solubilized and purified hSGLT1 needs to be tested. A transport assay was done in DPhPC planar lipid membranes (Fig. 7). Protein reconstitutes in a DPhPC lipid bilayer, ideally a single protein, and currents due to subsequent addition of hSGLT1 co-substrates and inhibitors were recorded (Fig. 7A). Histograms for currents values at $+100 \mathrm{mV}$ after the addition of $200 \mathrm{mM} \mathrm{K}^{+}$are not significantly different (ca. $0 \mathrm{pA}$ ) from those with $200 \mathrm{mM} \mathrm{K}^{+}$and $5 \mathrm{mM}$ glucose as hSGLT1 co-substrate (Fig. 7A). Adding $200 \mathrm{mM} \mathrm{Na}^{+}$as the second co-substrate increases the current values to ca. $300 \mathrm{pA}$. This large current change is unlikely to be caused by single protein insertion rather than the activity of multiple transporters inserted simultaneously in the DPhPC bilayer. Finally, the hSGLT1 activity was specifically inhibited to basal values (ca. $0 \mathrm{pA}$ ) using $100 \mu \mathrm{M}$ phlorizin. The same trend was observed when the experiments were performed at $+50,+100$, and $+150 \mathrm{mV}$ (Fig. $7 \mathrm{~B}$ and Supplementary Information).

\section{Discussion}

Membrane proteins are challenging structural biology targets, especially human membrane proteins. Outstanding advances have been achieved in the structural biology field for secondary transporters, especially by resolving structures of prokaryote homologues as a first approximation, such as the lactose and melibiose permeases $^{19,20}$. In the APC/SSS families, the structure of substrate-bound inward conformation for vSGLT has 


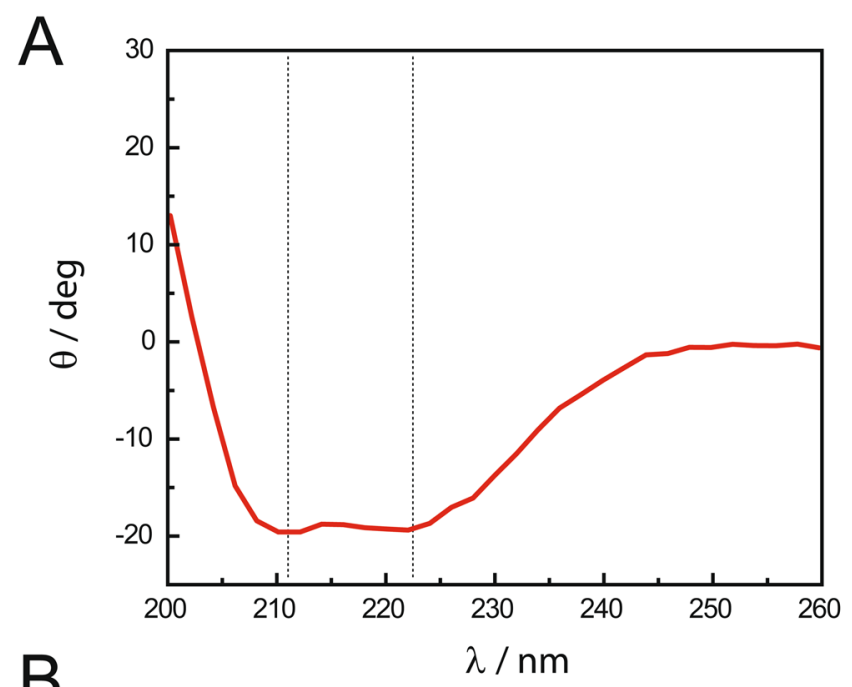

B

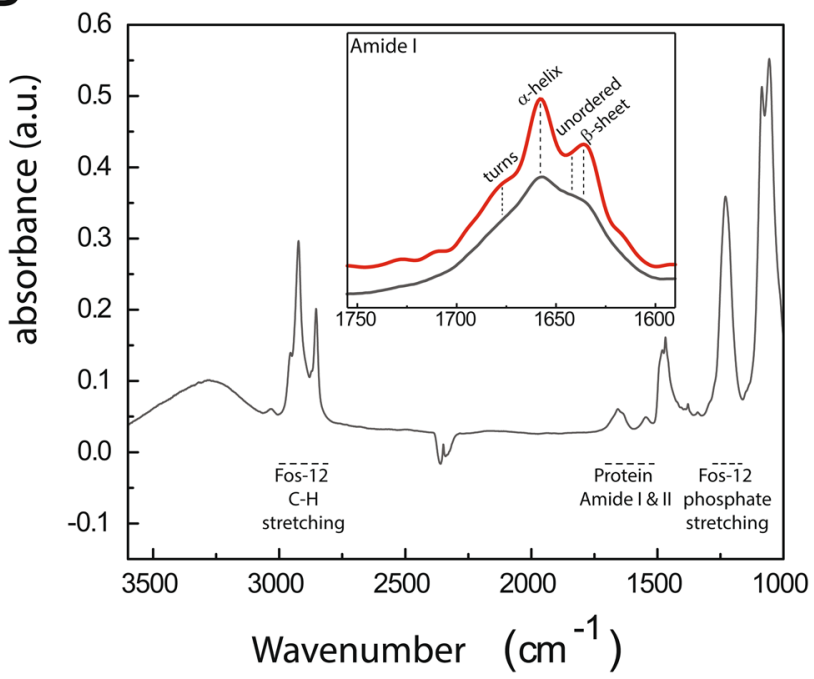

Figure 6. hSGLT1 secondary structure. (A) CD spectrum of WT hSGLT1 at 15 $\mu \mathrm{M}$ in $150 \mathrm{mM}$ TKCL at pH 7.6. (B) FT-IR spectrum of purified WT hSGLT1 in detergent micelles. Complete FT-IR spectrum of WT hSGLT1 after drying it out under $\mathrm{N}_{2}$ stream. Amide I region is magnified and specific regions are represented: $(\alpha)$ $\alpha$-helix at $1657 \mathrm{~cm}^{-1}$ and $(\beta) \beta$-sheet structure at $1635 \mathrm{~cm}^{-1}$. In black, dry FT-IR spectrum of WT hSGLT1 and, in red, dry FT-IR spectrum after deconvolution.

helped understanding the molecular alternating access mechanism of sodium-sugar transport ${ }^{18}$. The structure of vSGLT confirmed the prediction of 14 TM topology with both N- and C-termini facing the extracellular space ${ }^{21}$. The core structure for vSGLT is formed by two inverted repeats domain consisting of 5 TM helices each (TM2-6 and TM7-11) which is a very similar folding that has been observed for other non-active glucose transporters of 12 TM helices like in GLUT1,3, $5^{22}$. vSGLT and hSGLT1 present a high sequence identity and similarity (32 and $75 \%$, respectively), but structural biology efforts have not yielded the 3D structure for hSGLT1, although overexpression of this transporter has been achieved in Pichia $^{23}$. At present, the lack of 3D structural data on hSGLT1 prevents the understanding of specific structural details on human sodium-glucose transport. A main trait of hSGLT1 still remains controversial, which is the large cytosolic loop between helices TM13 and TM14, which has even been hypothesized as extracellular loop key to the formation of a vestibule for the sugar substrates ${ }^{24,25}$. Structural biology of hSGLT1 is key for the development of effective pharmacological strategies directed to GGM, diabetes, and cholera, and other diseases dependent on intestinal glucose absorption ${ }^{4,16,17}$.

Here we describe a P. pastoris based strategy to produce large amounts of recombinant functional hSGLT1 for biochemical and biophysical studies, as a starting material for structural biology studies. Our P. pastoris strategy includes several approaches for a quick screening of conditions to ease the expression and purification, secondary structure characterization, and functional assessment of any membrane protein of choice using P. pastoris as expression host. Regarding clone selection, multiple copy integration events are more likely to occur (1-10\% frequency) when the transformation method is electroporation and high amount of linearized vector is used (in the microgram range $)^{26}$. Higher number of plasmid integration events are expected to yield higher protein expres$\operatorname{sion}^{27}$, arguing for the relevance of the clone screening step (Fig. 2). With our approach we have been able to select the best expressing Pichia strains for the non-fluorescent and fluorescent constructs (Fig. 2). Overexpression of 


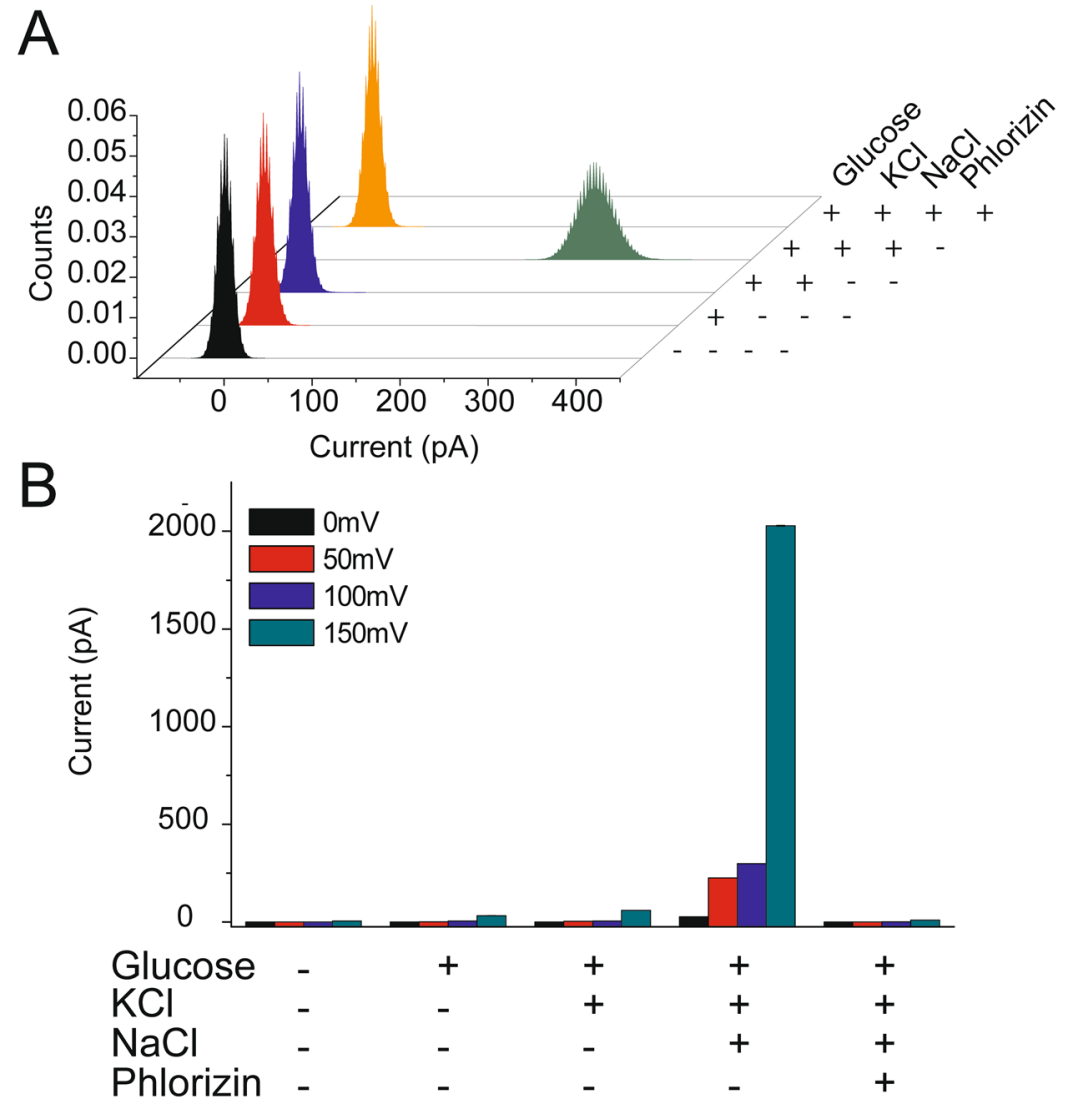

Figure 7. Functional characterization of hSGLT1 in planar lipid membranes. (A) Histogram of patch clamp measurements in planar lipid membranes at $100 \mathrm{mV}$. Histograms result from the evaluation of 4 seconds traces corresponding to: first addition of $10 \mathrm{ng}$ of protein to the planar membrane (black); addition of $5 \mathrm{mM}$ glucose to protein (red); addition of $200 \mathrm{mM} \mathrm{KCl}$ (blue); addition of $200 \mathrm{mM} \mathrm{NaCl}$ (green); addition of hSGLT1 inhibitor, phlorizin $(100 \mu \mathrm{M}$, orange). All additions were done consecutively after protein was initially added (black histogram). (B) Overall data of planar lipid membranes measurements at $0 \mathrm{mV}, 50 \mathrm{mV}, 100 \mathrm{mV}$ and $150 \mathrm{mV}$. An average of intensity was used after 4 seconds of recording.

membrane proteins easily leads to protein aggregation and accumulation in inclusion bodies or in specific degradation compartments (yeast vacuole) ${ }^{13}$. To monitor subcellular localization, imaging techniques taking advantage of the GFP fluorescence allowed us to detect non-aggregated eGFP-tagged proteins in membrane compartments different from the vacuole (Fig. 3). Previous studies on hSGLT1 expressed in Pichia identified Fos-12 as the most suitable detergent for solubilization ${ }^{23}$. Our detergent screening (Fig. 4) did not find a better suited detergent, but we provide insightful detail on the most adequate solubilization ratio (yeast membranes:detergent, see methods section for details). We have obtained a monodisperse hSGLT1 protein suitable for biophysical and biochemical studies (Fig. 5 and Supplementary Information), with a predominant $\alpha$-helix secondary structure (Fig. 6) expected for a protein with a 14TM predicted topology.

Specifically for hSGLT1, and in general for membrane proteins, we have used several experimental setups for membrane protein expression, such as the use of yeast as an inexpensive expression host ${ }^{13}$, GFP-based strategies ${ }^{28}$, rapid clone selection strategies ${ }^{29}$ and accessible secondary structure characterization, such as $\mathrm{CD}$. Additionally, we have included in the structural biology pipeline strategies such as quick secondary structure assessment of detergent solubilized membrane proteins using FTIR spectroscopy and mathematical deconvolution (Fig. 6B), which could be of further use in liposome reconstituted membrane proteins ${ }^{30}$. We have been able to assess the functionality of a detergent-solubilized membrane protein transporter without the hassle of liposome reconstitution, as a limiting step for protein function validation in structural studies ${ }^{31,32}$. Fluorescence and radioactivity experiments have been used to indirectly assess protein function using hSGLT1 purified from Pichia solubilized in detergent and reconstituted into liposomes ${ }^{23,33}$. Indirect assessments of substrate and/or inhibitor binding/ uptake function using Trp are not devoid of controversy, mainly because the lack of specificity and the need liposome reconstitution of the protein to assess sugar uptake, and mutagenesis to validate the specificity of binding in the presence of substrate or inhibitors such as phlorizin ${ }^{33}$. Phlorizin is the inhibitor of choice for hSGLT1, but the characteristic aromatic nature for this compound overlaps with the protein intrinsic Trp emission range, preventing the usage of this method for quick validation of hSGLT1 in detergent-solubilized or liposome reconstituted systems ${ }^{23,33}$. Our approach to use lipid planar membranes has been widely used as an electrophysiology method for membrane active peptides ${ }^{34}$, ion channels ${ }^{35}$, or proteins with a high electrogenic potential ${ }^{36}$. In this study, we have used this method not as a single channel measurement, but as a quick electrophysiological assessment 
for function of a secondary active sugar co-transporter, such as hSGLT1. Although our lipid planar membranes setup is home-assembled, electrophysiological devices ready for pharmacological high-throughput screening of ion channels, and transporters are becoming readily available, an in fact some of them are being used to specifically assess hSGLT1 pharmacology ${ }^{37}$. We believe our screening strategy for protein expression and purification, including secondary structure and functional characterization with detergent solubilized protein will be of use for biophysics and structural biology laboratories requiring high amounts of membrane proteins, especially when considering human or mammalian orthologues. For hSGLT1, this strategy has produced unsuccessful crystallization attempts, which is the limiting step before tridimensionl high-resolution structure.

\section{Methods}

Materials. The P. pastoris strain (SMD1168H) was supplied by Thermo Fisher Scientific. Restriction enzymes NdeI, Not1 and PmeI were from New England Biolabs (London, Great Britain). Plate reader was FLUOstar optima from BMG Labtech (Germany, Ortenberg). Superose 6 Increase 10/300 GL, Superdex 200 10/300 GL and Ni-NTA column were obtained from GE Healthcare. Phlorizin, Glucose and FLAG-tag resin were from Sigma-Aldrich. Detergents were purchased from Anatrace and kept at $-20^{\circ} \mathrm{C}$. All other non-specific chemical reagents were of analytical grade and obtained from commercial source.

Construction of expression vectors. The full-length hSGLT1 with a FLAG tag position at $\mathrm{D}_{574}$ was cloned into $\mathrm{pP}$ expression vector (derived from $\mathrm{pPCIZB}$ vector). The FLAG tag position changed the natural peptide sequence from $\mathrm{D}_{574}$ AEEN to $\mathrm{D}_{574}$ YKDDDDK. Coding DNA of hSGLT1 was amplified by polymerase chain reaction using the following primers: sense, $5^{\prime}$-ATT-AAG-CAT-ATG-GAC-AGT-AGC-ACC-TGG-3' ${ }^{\prime}$, and antisense, 5'-TTA-ATA-TGC-GGC-CGC-GGC-AAA-ATA-TGC-ATG-GCA-AAA-3'. The cDNA sequence of hSGLT1 was cloned into NotI and NdeI sites of pP and pP-eGFP. The N248A mutant was done by KOD polymerase Quikchange reaction using $\mathrm{pP}-\mathrm{hSGLT}$ and $\mathrm{pP}$ - as template and with the following primers: sense, $5^{\prime} \mathrm{GTGTCTG}$ ATGGCGCCACCACCTTTCAGG3', and antisense, 5' CCTGAAAGGTGGTGGCGCCATCAGACAC $3^{\prime}$. The final expression products were hSGLT1 fused to 8xHistidine tag and hSGLT1 fused to an enhanced GFP (eGFP) followed by a 8 XHis-tag. Both resulting plasmids were transformed into $E$. coli cells for further amplification and purification of the resulting plasmid. Both plasmids constructs were verified by DNA sequencing.

Electroporation of $P$. pastoris with plasmid pP-hSGLT1 and pP-hSGLT1-eGFP. The purified DNA samples of pP-hSGLT1 and pP-hSGLT1-eGFP were linearized by PmeI digestion at $37^{\circ} \mathrm{C}$ overnight. Linearized DNA was purified by enzyme removal column in order to remove remaining salts which hamper electroporation.

YPD medium $(10 \mathrm{~mL})$ was inoculated with $P$. pastoris strain $\mathrm{SMD} 1168 \mathrm{H}$ and culture was grown overnight at $30^{\circ} \mathrm{C}$. The culture was transferred into $500 \mathrm{~mL}$ of fresh YPD at $30^{\circ} \mathrm{C}$ until reaching an $\mathrm{OD}_{600}$ of 1 . Cells were harvested by centrifugation at $2.000 \mathrm{~g}$ at $4^{\circ} \mathrm{C}$ for 5 minutes and were suspended in YPD medium plus HEPES (pH $8.0,200 \mathrm{mM}$ ) and $5 \mathrm{mM}$ DTT in a new flask. The culture was incubated at $30^{\circ} \mathrm{C}, 100 \mathrm{rpm}$ for 15 minutes. $150 \mathrm{~mL}$ of cold sterile water was added into the culture and it was centrifuged at $2000 \mathrm{~g}$ at $4^{\circ} \mathrm{C}$ for 5 minutes. The cell pellet was suspended in $250 \mathrm{~mL}$ of cold sterile water and centrifuged. The pellet was suspended again in $20 \mathrm{~mL}$ of ice-cold sterile sorbitol $1 \mathrm{M}$. Finally, the culture was centrifuged and the resulting pellet was suspended in $1 \mathrm{~mL}$ of ice-cold sterile $1 \mathrm{M}$ sorbitol. All suspensions must be done by gently shacking or slowly pipetting. Competent cells were kept in ice and used immediately or aliquoted and frozen at $-80^{\circ} \mathrm{C}$.

For electroporation, the suspension of competent cells $(40 \mu \mathrm{L})$ was mixed with lyophilized linearized DNA $(24 \mu \mathrm{g})$ from PmeI digestion and transferred to an ice-cold electroporation cuvette. The cuvette with the mixture of cells and DNA was incubated on ice for 5 minutes. Cells were pulsed at $1.5 \mathrm{kV}$ and $1 \mathrm{~mL}$ of ice-cold sorbitol was added immediately. Electroporated cells were transferred to recover in an incubator at $30^{\circ} \mathrm{C}$ at $100 \mathrm{rpm}$ for 3-4 hours. $200 \mu \mathrm{L}$ of these cells were plated on YPD medium with 100 and $500 \mu \mathrm{g} / \mathrm{mL}$ of zeocin and incubated at $30^{\circ} \mathrm{C}$ until colonies appear.

Selection of multiple copy recombinant genes of $P$. pastoris transformants by serial dilution: zeocin viability. Transformed colonies of pP-hSGLT1 were streaked in a new YPD medium plate with $100 \mu \mathrm{g} / \mathrm{mL}$ of zeocin at $30^{\circ} \mathrm{C}$ for 48 hours. Each transformant colony and a negative control (non-transformed SMD $1168 \mathrm{H}$ colony) were inoculated in $5 \mathrm{~mL}$ of YPD medium and were left to grow at $30^{\circ} \mathrm{C}$ overnight. Cells were harvested by centrifugation at $2,000 \times \mathrm{g}$ and resuspended in distilled-sterilized water. $\mathrm{OD}_{600}$ measures were taken for each culture and $1 \mathrm{~mL}$ was set aside to a final normalized $\mathrm{OD}_{600}$ of 1 . Serial dilutions were done for each culture: $10^{0}, 10^{-1}, 10^{-2}, 10^{-3}$, and $10^{-4}$. A drop test of $5 \mu$ of each colony and their dilution was done in YPD medium plate with 100 and $500 \mu \mathrm{g} / \mathrm{mL}$ of zeocin. Plates were left to grow at $30^{\circ} \mathrm{C}$ for 48 hours or until colonies appeared.

Selection of multiple copy recombinant genes of $P$. pastoris transformants by in-plate induction. Transformed colonies of pP-hSGLT1-eGFP were streaked in a new YPD medium plate with $100 \mu \mathrm{g} / \mathrm{mL}$ zeocin at $30^{\circ} \mathrm{C}$ for 48 hours. Each transformant colony, a positive control (pP-eGFP empty vector) and a non-transformed P. pastoris colony (SMD1168H) was inoculated in $5 \mathrm{~mL}$ of YPD medium and was left to grow at $30^{\circ} \mathrm{C}$ overnight. Cells were harvested by centrifugation at $2000 \times \mathrm{g}$ to remove YPD medium and suspended in minimal methanol $(\mathrm{MM})$ medium. $\mathrm{OD}_{600}$ measurements were taken for each culture and $100 \mu \mathrm{l}$ were set aside and normalized to a final $\mathrm{OD}_{600}$ of 1 . A drop test of $5 \mu \mathrm{l}$ of each colony was done in $\mathrm{MM}$ plates which were transferred to an incubator at $30^{\circ} \mathrm{C}$ for 48 hours. The plate was transilluminated with an eGFP fluorescence filter at $550 \mathrm{~nm}$.

Subcellular protein localization: Confocal microscopy. A selected expression clone of pP-hSGLT1-eGFP and a transformed pP-eGFP empty vector clone were inoculated in $25 \mathrm{~mL}$ of MM medium at $30^{\circ} \mathrm{C}$ overnight. Cells were harvest by centrifugation at $2000 \times \mathrm{g}$ and suspended in $25 \mathrm{~mL}$ of MM medium. Cultures were transferred back to an incubator at $24^{\circ} \mathrm{C}$ for 48 hours. Small aliquots $(50 \mu \mathrm{L})$ were removed at 
different times: 4, 8, 12 and 24 hours. Cells were normalized to and $\mathrm{OD}_{600}$ of 1 . A drop of $5 \mu$ of cells was put on a slide covered with a coverslip. A bright field picture and a fluorescence picture were taken at higher magnification after adding a drop of immersion oil as explained in $^{12}$.

Membranes preparation and large scale cell cultures. Large scale P. pastoris culture was grown in $200 \mathrm{~mL}$ of buffered minimal glycerol (BMG) medium at $24^{\circ} \mathrm{C}$ for 24 hours. The culture was transferred into $4 \mathrm{~L}$ of BMG medium and was left to grow for 48 hours but adding Glycerol 1\% (w/v) after 24 hours. The culture was spun down at 2,000 $\times \mathrm{g}$ and was suspended into buffered minimal methanol (BMM) medium and transferred to an incubator at $24^{\circ} \mathrm{C}$ for $20-24$ hours for protein induction. The culture was harvested after centrifugation at 2,000 $\times \mathrm{g}$ and suspended in distilled water to remove traces of BMM. Culture was spun down once more at $2,000 \times \mathrm{g}$ and the cell pellet was frozen with liquid nitrogen and stored at $-80^{\circ} \mathrm{C}$.

The cell culture was slowly thawed at $4^{\circ} \mathrm{C}$. Up to $80 \mathrm{~g}$ of cells were resuspended with a vortex in a total volume of $175 \mathrm{~mL}$ of ice-cold breaking buffer (50 mM Tris-HCl, $1 \mathrm{mM}$ EDTA, 5\% (w/v) Glycerol, $0.1 \mathrm{mM} \mathrm{PMSF}, 10 \mathrm{mM}$ DTT). Protease inhibitor cocktail (Complete, Roche) and an equal volume of glass beads $(0.5 \mathrm{~mm})$ were added to the suspension and cells were broken by mechanical disruption in a bead beater at $4{ }^{\circ} \mathrm{C}$. Up to 20 cycles of 1 minute were carried out for cell disruption with 2 minutes interposition after each cycle to prevent heating. Unbroken cells were removed by centrifugation at $3,000 \times \mathrm{g}$ for 10 minutes. The supernatant was centrifuged at $100,000 \times \mathrm{g}$ for 1 hour to recover the membrane fraction, which was then flash frozen with liquid nitrogen.

Detergent Screening. Membranes were thawed slowly and homogenized in TKCL (20 mM Tris- $\mathrm{HCl}$, $150 \mathrm{mM} \mathrm{KCl}, 1 \mathrm{mM} \mathrm{DTT} \mathrm{pH} \mathrm{7.6)} \mathrm{and} \mathrm{solubilized} \mathrm{for} 2$ hours at $4^{\circ} \mathrm{C}$ by adding specific detergents at $3 \mathrm{x}$ critical micellar concentration (CMC) for initial screening (detergents are listed in Fig. 4a). Non-soluble aggregates were removed by centrifugation at $25,000 \times \mathrm{g}$ for 30 minutes and up to $200 \mu \mathrm{L}$ of each sample were taken to a plate reader and a fluorescence measure was recorded with an excitation/emission filter set at $485 \mathrm{~nm}$ and $520 \mathrm{~nm}$ respectively. For each tested detergent, two measures were recorded: total solubilized membranes before ultracentrifugation and supernatant of ultracentrifugation so a percentage of fluorescence recovery could be calculated. A further analysis was done by fluorescence size exclusion chromatography (FSEC) for most commonly used detergents as described in ${ }^{13}$, such as: Fos-Choline-12 (Fos-12), n-Dodecyl- $\beta$-D-Maltopyranoside (DDM), n-Decyl- $\beta$-D-Maltopyranoside (DM), n-Octyl Glucoside (OG) and N,N-Dimethyldodecylamine N-oxide $(\mathrm{LDAO})$ at $1 \%(\mathrm{w} / \mathrm{v})$ concentration. Membranes were homogenized and solubilized with the same conditions stated before. Non-soluble aggregates were removed by centrifugation at $50,000 \times \mathrm{g}$ for 30 minutes. $5 \mu \mathrm{L}$ of the resulting supernatant were injected into a Superose 6 column through a HPLC system. A high sensitivity program was used with an excitation/emission wavelength at $480 / 510 \mathrm{~nm}$.

Protein purification. Membranes were thawed slowly and homogenized in TKCL buffer at a specific ratio $(\mathrm{w} / \mathrm{v})$ of 0.16 (grams of membrane/total volume of solubilization) at $1.2 \%(\mathrm{w} / \mathrm{v})$ of Fos-12 for 2 hours. Solubilized membranes were spun down at $50.000 \times \mathrm{g}$ for 45 minutes and the clean supernatant was recovered. The supernatant was poured to a $5-\mathrm{mL}$ bed (1-cm diameter) of $\mathrm{Ni}^{+2}$ chelate to resin (nickel-nitrilotriacetic, Ni-NTA) which was previously equilibrated with 5 column volumes (CV) of TKCL at $1.2 \%$ of Fos- $12(\mathrm{w} / \mathrm{v})$. The resin with the solubilized membranes was left in batch mode for $3-4$ hours at $4{ }^{\circ} \mathrm{C}$ with slow shaking in a beaker. The resin was transferred back into a column and left to pack again by starting the flow. A washing step of 5 CV of TKCL at $0.2 \%$ (w/v) of Fos-12 without imidazole was done followed by another washing step of $10 \mathrm{CV}$ but with $10 \mathrm{mM}$ imidazole. The protein was eluted with an elution step of 5 CV of TKCL at $0.2 \%(\mathrm{w} / \mathrm{v})$ of Fos- 12 with $150 \mathrm{mM}$ imidazole (higher imidazole concentrations can be used up to $250 \mathrm{mM}$ ). His-tagged eluted protein fractions were pooled and concentrated with a Centricon (Millipore) to $0.5-1 \mathrm{~mL}$ final volume. Concentrated fraction was centrifuged at $50.000 \times \mathrm{g}$ for 20 minutes to pellet any aggregates and then applied to a Superdex $200 \mathrm{HR} 10 / 30$ gel filtration column equilibrated previously in TKCL at $0.2 \%$ Fos- 12 (w/v). An ÄKTA purifier system was used for the SEC purification at a flux of $0.4 \mathrm{ml} / \mathrm{min}$. Eluted fractions of the elution were pooled together and stored at $-4^{\circ} \mathrm{C}$.

Another affinity purification step (FLAG-tag) may be added between the Ni-NTA purification and the SEC depending on the required sample purity. Initially, imidazole was lowered down from the purified protein sample from the Ni-NTA with a Centricon to $10 \mathrm{mM}$. Ni-NTA purified sample was poured to $4-\mathrm{mL}$ bed $(1.5-\mathrm{cm}$ diameter) of FLAG-tag resin (Sigma) which was previously equilibrated in $2 \mathrm{CV}$ of high salt TKCL (20 mM Tris, $500 \mathrm{mM} \mathrm{KCl}, 1 \mathrm{mM}$ DTT, pH 7.6) at $0.2 \%$ (w/v) of Fos- 12 and left in batch mode overnight at $4{ }^{\circ} \mathrm{C}$. The resin was repacked by restarting the flow and washed with high salt TKCL until no protein was observed in the washes. Elution was done with $5 \mathrm{CV}$ of FLAG-tag elution buffer (200 mM Glicine, $150 \mathrm{mM} \mathrm{KCl}, 1 \mathrm{mM}$ DTT pH 3.5) at $0.2 \%(\mathrm{w} / \mathrm{v})$ of Fos- 12 which was immediately neutralized with $1 \mathrm{M}$ Tris- $\mathrm{HCl}$ at $\mathrm{pH} 8.0$ to equilibrate the final $\mathrm{pH}$.

SDS-PAGE and Immunoblotting. $\quad 8$ or 10\% SDS-PAGE gels were run at $120 \mathrm{~V}$. For in-gel fluorescence of eGFP fusion proteins gels were illuminated using blue light transilluminator. Subsequently gels were commassie blue-stained or transferred using a semi-dry blot device to nitrocellulose membranes. Nitrocellulose membranes were blocked with 5\% BSA for 1 hour. Primary antibodies against hSGLT1 (1:5000 hSGLT1-rabbit, Cat. No. AP00343PU-N Acris antibodies), eGFP (1:1000, DHSB Cat. No. GFP-G1), and His-tag (1:8000, DHSB Cat. No. P5A11). Secondary antibody incubation was followed up by detection using the Immobilon Western kit (Millipore).

Structural characterization: Fourier transform infrared spectroscopy (FTIR) spectroscopy and circular dichroism (CD). Purified protein in micelles in TKCL at $3 \mathrm{mg} / \mathrm{mL}$ was used to record FT-IR and CD spectra. CD spectrum of WT hSGLT1 was taken at $15 \mu \mathrm{M}$ in $150 \mathrm{mM}$ TKCL at pH 7.6. Measures were taken in cuvette with an optical path of $1 \mathrm{~mm}$ in a JASCO J-715 spectropolarimeter. FTIR spectra were recorded with a Varian 7000Fourier transform spectrometer equipped with a attenuated total reflection (ATR) diamond crystal 
at room temperature at a resolution of $2 \mathrm{~cm}^{-1}$. The sample chamber was purged continuously with $\mathrm{N}_{2}$ in order to remove water vapor.

Planar lipid membranes preparation and transport studies. Planar bilayers were formed by apposition of two monolayers prepared from a solution of $1 \%$ pure diphytanoyl phosphatidylcholine (DPhPC) in pentane. $10 \mu \mathrm{L}$ lipids at $5 \mathrm{mg} / \mathrm{mL}$ were added on $70-90 \mu \mathrm{m}$ diameter orifice in the $15 \mu \mathrm{m}$ thick Teflon partition that separated two identical chambers $(25,26)$. The orifice was pretreated with $1 \%$ hexadecane in pentane before adding the lipids. Aqueous solutions of chambers were buffered with $50 \mathrm{mM} \mathrm{HEPES} \mathrm{at} \mathrm{pH} 7$ and $100 \mathrm{mM} \mathrm{KCl}$. All measurements were done at room temperature $\left(23-25^{\circ} \mathrm{C}\right)$. Control experiments assured that lipid bilayers without any protein addition were totally impermeable. Membrane permeabilization was achieved by adding $1-5 \mu \mathrm{L}$ of purified protein (hSGLT1) at $2.5 \mathrm{mg} / \mathrm{mL}$ in TKCL $(20 \mathrm{mM}$ Tris, $150 \mathrm{mM} \mathrm{KCl}, 1 \mathrm{mM} \mathrm{DTT} \mathrm{pH} 7.6)$ at $0.2 \%$ Fos- 12 into the chamber.

An electric potential was applied using $\mathrm{Ag} / \mathrm{AgCl}$ electrodes in $2 \mathrm{M} \mathrm{KCl}, 1.5 \%$ agarose bridges assembled within standard $250 \mu \mathrm{L}$ pipette tips. The potential was defined as positive when it was higher on the side of the protein addition (cis side), whereas the trans side was set to ground. An Axopatch 200B amplifier in the voltage-clamp mode was used to measure the current and the applied potential. The chamber and the head stage were isolated from external noise sources with a double metal screen. Current traces were recorded at several applied voltages: 150,100 , and $50 \mathrm{mV}$. Small intensities (5-20 pA) revealed protein insertion into the membrane and, in that case, substrates (glucose and sodium) and inhibitor (phlorizin) were added successively. In particular, $200 \mathrm{mM} \mathrm{NaCl}$ (specific-transport ion) was used and intensity was recorded at each specified voltage. Same protocol was used for $200 \mathrm{mM} \mathrm{KCl}$ (non-specific-transport ion), $5 \mathrm{mM}$ glucose, and $100 \mu \mathrm{M}$ phlorizin.

Mass spectrometry. WT hSGLT1 purified protein after FLAG-tag and SEC chromatography was treated with DTT $500 \mathrm{mM}$ for 15 minutes at room temperature. Afterwards, protein was precipitated with chloroform and methanol and then dissolved in $20 \mu \mathrm{L} 90 \%$ formic acid for immediate analysis by size-exclusion liquid chromatography with positive ion electrospray ionization mass spectrometry $(\mathrm{LC}-\mathrm{MS})^{38}$. The column $(4.6 \times 300 \mathrm{~mm}$; Tosoh SW2000) was equilibrated in chloroform/methanol/ $1 \%$ aqueous formic acid $(4 / 4 / 1 ; \mathrm{v} / \mathrm{v})$ at $40^{\circ} \mathrm{C}$ with a flow rate of $250 \mu \mathrm{L} / \mathrm{min}$. and eluted into the source of a linear ion-trap mass spectrometer (LTQ, Thermofisher Scientific). Protein mass spectra were deconvoluted using BioMultiview software (Sciex).

\section{References}

1. Wallin, E. \& Heijne, G. V. Genome-wide analysis of integral membrane proteins from eubacterial, archaean, and eukaryotic organisms. Protein Sci. 7, 1029-1038 (2008).

2. Almen, M. S., Nordstrom, K. J. V., Fredriksson, R. \& Schioth, H. B. Mapping the human membrane proteome: a majority of the human membrane proteins can be classified according to function and evolutionary origin. BMC Biol. 7, 50 (2009).

3. Sanders, C. R. \& Nagy, J. K. Misfolding of membrane proteins in health and disease: the lady or the tiger? Curr. Opin. Struct. Biol. 10, 438-442 (2000)

4. Wright, E. M., Hirayama, B. A. \& Loo, D. F. Active sugar transport in health and disease. J. Intern. Med. 261, 32-43 (2007).

5. Locher, K. P., Bass, R. B. \& Rees, D. C. Structural biology. Breaching the barrier. Science 301, 603-604 (2003).

6. Lieberman, R. L., Peek, M. E. \& Watkins, J. D. Determination of soluble and membrane protein structures by X-ray crystallography. Methods Mol. Biol. 955, 475-493 (2013).

7. Lyons, J. A., Shahsavar, A., Paulsen, P. A., Pedersen, B. P. \& Nissen, P. Expression strategies for structural studies of eukaryotic membrane proteins. Curr. Opin. Struct. Biol. 38, 137-144 (2016).

8. Tokmakov, A. A. et al. Multiple post-translational modifications affect heterologous protein synthesis. J. Biol. Chem. 287, 27106-27116 (2012).

9. Eckart, M. R. \& Bussineau, C. M. Quality and authenticity of heterologous proteins synthesized in yeast. Curr. Opin. Biotechnol. 7, 525-530 (1996)

10. Cereghino, J. L. \& Cregg, J. M. Heterologous protein expression in the methylotrophic yeast Pichia pastoris. FEMS Microbiol. Rev. 24, 45-66 (2000).

11. Cregg, J. M., Cereghino, J. L., Shi, J. \& Higgins, D. R. Recombinant protein expression in Pichia pastoris. Mol. Biotechnol. 16, 23-52 (2000).

12. Newstead, S., Kim, H., von Heijne, G., Iwata, S. \& Drew, D. High-throughput fluorescent-based optimization of eukaryotic membrane protein overexpression and purification in Saccharomyces cerevisiae. Proc. Natl. Acad. Sci. 104, 13936-13941 (2007).

13. Drew, D. et al. GFP-based optimization scheme for the overexpression and purification of eukaryotic membrane proteins in Saccharomyces cerevisiae. Nat. Protoc. 3, 784-798 (2008)

14. Mizutani, K., Yoshioka, S., Mizutani, Y., Iwata, S. \& Mikami, B. High-throughput construction of expression system using yeast Pichia pastoris, and its application to membrane proteins. Protein Expr. Purif. 77, 1-8 (2011)

15. Hediger, M. A., Coady, M. J., Ikeda, T. S. \& Wright, E. M. Expression cloning and cDNA sequencing of the Na+/glucose cotransporter. Nature 330, 379-81 (1987).

16. Turk, E., Zabel, B., Mundlos, S., Dyer, J. \& Wright, E. M. Glucose/galactose malabsorption caused by a defect in the Na+/glucose cotransporter. Nature 350, 354-356 (1991).

17. Washburn, W. N. Development of the renal glucose reabsorption inhibitors: a new mechanism for the pharmacotherapy of diabetes mellitus type 2. J. Med. Chem. 52, 1785-1794 (2009).

18. Faham, S. et al. The crystal structure of a sodium galactose transporter reveals mechanistic insights into $\mathrm{Na}+/$ sugar symport. Science 321, 810-814 (2008).

19. Abramson, J. et al. Structure and mechanism of the lactose permease of Escherichia coli. Science 301, 610-615 (2003).

20. Ethayathulla, A. S. et al. Structure-based mechanism for Na(+)/melibiose symport by MelB. Nat. Commun. 5, 3009 (2014).

21. Chen, X. Z., Coady, M. J., Jackson, F., Berteloot, A. \& Lapointe, J. Y. Thermodynamic determination of the Na+: glucose coupling ratio for the human SGLT1 cotransporter. Biophys. J. 69, 2405-2414 (1995).

22. Deng, D. et al. Molecular basis of ligand recognition and transport by glucose transporters. Nature 526, 391-396 (2015).

23. Tyagi, N. K. et al. High-yield functional expression of human sodium/d-glucose cotransporter1 in Pichia pastoris and characterization of ligand-induced conformational changes as studied by tryptophan fluorescence. Biochemistry 44, 15514-15524 (2005).

24. Raja, M. M., Kipp, H. \& Kinne, R. K. H. C-terminus loop 13 of Na+ glucose cotransporter SGLT1 contains a binding site for alkyl glucosides. Biochemistry 43, 10944-10951 (2004). 
25. Raja, M. M. \& Kinne, R. K. H. Interaction of C-terminal loop 13 of sodium-glucose cotransporter SGLT1 with lipid bilayers. Biochemistry 44, 9123-9129 (2005).

26. Cregg, J. M. et al. Chapter 13 Expression in the Yeast Pichia pastoris. Methods in Enzymology 463 (Elsevier Inc., 2009).

27. Byrne, B. Pichia pastoris as an expression host for membrane protein structural biology. Curr. Opin. Struct. Biol. 32, 9-17 (2015).

28. Kawate, T. \& Gouaux, E. Fluorescence-Detection Size-Exclusion Chromatography for Precrystallization Screening of Integral Membrane Proteins. Structure 14, 673-681 (2014).

29. Brooks, C. L. \& Morrison, M. \& Joanne Lemieux, M. Rapid expression screening of eukaryotic membrane proteins in Pichia pastoris. Protein Science: A Publication of the Protein Society 22, 425-433 (2013).

30. Granell, M., León, X., Leblanc, G., Padrós, E. \& Lórenz-Fonfría, V. A. Structural insights into the activation mechanism of melibiose permease by sodium binding. Proc. Natl. Acad. Sci. USA 107, 22078-22083 (2010).

31. Rigaud, J.-L. Membrane proteins: functional and structural studies using reconstituted proteoliposomes and 2-D crystals. Brazilian J. Med. Biol. Res. = Rev. Bras. Pesqui. medicas e Biol. 35, 753-766 (2002).

32. Parmar, M. M., Edwards, K. \& Madden, T. D. Incorporation of bacterial membrane proteins into liposomes: factors influencing protein reconstitution. Biochim. Biophys. Acta - Biomembr. 1421, 77-90 (1999).

33. Tyagi, N. K. et al. D-Glucose-recognition and phlorizin-binding sites in human sodium/D-glucose cotransporter 1 (hSGLT1): a tryptophan scanning study. Biochemistry 46, 13616-13628 (2007).

34. Largo, E., Verdia-Baguena, C., Aguilella, V. M., Nieva, J. L. \& Alcaraz, A. Ion channel activity of the CSFV p7 viroporin in surrogates of the ER lipid bilayer. Biochim. Biophys. Acta 1858, 30-37 (2016).

35. Kol, S. et al. Heterologous expression and purification of an active human TRPV3 ion channel. FEBS J. 280, 6010-21 (2013).

36. Villalobo, A. Reconstitution of ion-motive transport ATPases in artificial lipid membranes. Biochim. Biophys. Acta 1017, 1-48 (1990).

37. Weinglass, A. B., Garcia, M. L. \& Kaczorowski, G. L. Technologies for transporter drug discovery. Channels 2, 312-321 (2008).

38. Wessel, D. \& Flugge, U. I. A method for the quantitative recovery of protein in dilute solution in the presence of detergents and lipids. Anal. Biochem. 138, 141-143 (1984).

\section{Acknowledgements}

The cDNA sample for human SGLT1 was kindly provided by Prof. R.K.H. Kinne. pP and pP-eGFP vectors were kindly provided by Prof. Rachelle Gaudet. We want to acknowledge Prof. E.M. Wright, Prof. J. Abramson, and Dr. T. Althoff for helpful technical discussions and kind access to UCLA facilities. This work was supported by the MICINN grants BFU2012-40137-C02-01 to J.C. and SAF2010-21385 to A.P.-M., and the NIH grant NIH P30 DK063491 to J.P.W.; A.P.-M. was a recipient of a Marie Curie International Outgoing Fellowship within the 7th European Community Framework Programme (PIOF-GA-2009-237120 to A.P.-M.) and a Universitat Autònoma de Barcelona-Programa Banco de Santander Fellowship. A.S. was a recipient of a Ph.D. fellowship and a travel bursary from Universitat Autònoma de Barcelona.

\section{Author Contributions}

A.P.-M., J.C. and J.M. designed the experiments and provided reagents. A.S., E.C. and E.A.-M. performed the experiments. A.A. supervised the lipid planar membranes experiments. J.P.W. supervised the mass spectrometry experiments. A.P.-M. and A.S. wrote the manuscript. All authors participated in data analysis, discussion of results, and critical reviewing of the manuscript.

\section{Additional Information}

Supplementary information accompanies this paper at https://doi.org/10.1038/s41598-018-37445-2.

Competing Interests: The authors declare no competing interests.

Publisher's note: Springer Nature remains neutral with regard to jurisdictional claims in published maps and institutional affiliations.

(c) Open Access This article is licensed under a Creative Commons Attribution 4.0 International

License, which permits use, sharing, adaptation, distribution and reproduction in any medium or format, as long as you give appropriate credit to the original author(s) and the source, provide a link to the Creative Commons license, and indicate if changes were made. The images or other third party material in this article are included in the article's Creative Commons license, unless indicated otherwise in a credit line to the material. If material is not included in the article's Creative Commons license and your intended use is not permitted by statutory regulation or exceeds the permitted use, you will need to obtain permission directly from the copyright holder. To view a copy of this license, visit http://creativecommons.org/licenses/by/4.0/.

(C) The Author(s) 2019 